\title{
Causes of Small Ruminants Liver Condemnation and Financial Loss at Abyssinia Slaughtering Service House, Bishoftu, Ethiopia
}

\author{
Gamachis Bulbula and Hailegebrael Bedada* \\ College of Veterinary Medicine, Samara University, Ethiopia
}

Submission: December 27, 2018; Published: January 22, 2019

*Corresponding author: Hailegebrael Bedada, College of Veterinary Medicine, Samara University, P.O. Box, 132, Samara, Ethiopia

\begin{abstract}
A study was conducted from November 2017 to April 2018 on sheep and goats slaughtered at Abyssinia Slaughtering Service House with the aim of determining major causes of liver condemnation and to estimate the direct financial losses attributed to the condemned liver. Ante mortem and post-mortem inspection procedures were followed throughout the study and abnormalities encountered were recorded. A total of 520 sheep and 510 goats were examined at ante mortem and all were passed for slaughter. Out of 1030 sheep and goats slaughtered, 381 (37\%) livers were totally condemned. The major causes of liver condemnation were due to hepatitis, calcification, cirrhosis, stelesia hepatica, C. tenuicollis, fasciola and adhesion. The principal causes of condemnation were hepatitis 56(10.8\%), calcification 47(9.04\%), Stelesia hepatica 47(9.04\%) and Fasciola $37(7.1 \%)$ in sheep and hepatitis $36(7.06 \%)$ and cirrhosis 33(6.5\%) in goats. Hepatitis was highest contributor in both species while calcification and Stelesia hepatica in sheep and cirrhosis in goat were mostly contributed to liver condemnation. Comparison of liver condemnation rate was carried out for different age, animal origin and species of animals. However, statistically significant difference was observed only between species (P-value=.000). The direct financial loss due to liver condemnation was calculated to be 58,018.4 ETB or 2,148.8 USD per annum, rendering them unfit for local market on esthetic ground or considering their zoonotic risks to human beings. To this end, public education on the effects of animal disease, application of strict control measures accompanying epidemiological studies and exercising appropriate meat inspection procedures were forwarded to minimize liver condemnation and as well as to safeguard the welfare of the public.
\end{abstract}

Keywords: ASSH; Condemnation; Financial Loss; Liver; Small ruminants

\section{Introduction}

Ethiopia has more domesticated animals than any other country in Africa and agriculture is the mainstay of economy. Ethiopia is believed to have the largest livestock population in Africa with estimated population of 54 million cattle, 25.5 million sheep and 24.06 million goats [1]. In Ethiopia, sheep are the second most important livestock species next to cattle and ranks second in Africa and sixth in the world in sheep population. Sheep play an important economic role and make a significant contribution to both domestic and export markets through provision of food (meat and milk) and non-food (manure, skin and wool) products. They also play a major role in the food security and social well-being of rural populations living under conditions of extreme poverty which is particularly the case for eastern parts of Ethiopia.

Despite the number of populations, their potential use is hampered by rampant animal diseases, poor nutrition, poor husbandry, poor infrastructure and shortage of trained man power and other constraints. Each year a significant loss results from death of animals, inferior weight gain, condemnation of edible organs and carcass at slaughter [2]. The primary aim of the abattoir is to produce healthy meat, wholesome and clean products which are safe for human consumption [3]. Besides, abattoirs provide information on the epidemiology of diseases on livestock, to know to what extent the public is exposed to certain zoonotic diseases and to estimate financial losses incurred through condemnation of affected organs and carcasses [4]. Surveillance at the abattoir allows for all animals passing in to human food chain to be examined for unusual signs, lesions or specific disease [5]. Ante-mortem inspection attempts to avoid introduction of clinically diseased animal into the slaughter house and serves to obtain information that were useful in making sound post- mortem inspection. The final judgment as to action to be taken with an organ, carcass or part of carcass was based on the total evidence produced by the visual observation, palpation and incision [6].

Several studies have been conducted through abattoir survey to estimate the prevalence of certain diseases and financial losses associated with organ and carcass condemnation in various parts 
of the country. However, most of the studies were concentrated only to some diseases particularly parasitic disease like fasciola, Hydatidosis, Cysticercosis $[7,8]$. Hence, it is indispensable to conduct comprehensive research to investigate the major problems attributable to organ and carcass condemnation at municipal and export abattoir in different parts of the country to get a clear picture of the problems at national level. Therefore, the objectives of the present study were; to identify the causes of liver condemnation at Bishoftu Abyssinia Slaughtering Service House and to assess the magnitude of direct financial losses.

\section{Materials and Methods}

\section{Study Area and Study Population}

The study was conducted in Bishoftu town at Abyssinia Slaughtering Service House, East Showa zone of Oromia regional state. The area is located at $9^{\circ} \mathrm{N}$ latitude and $40^{\circ} \mathrm{E}$ longitude at altitude of 1850 masl with annual rain fall of $866 \mathrm{~mm}$ of which $84 \%$ is in the long rainy season June to September. The annual average temperature ranges from $12.3^{\circ} \mathrm{C}$ to $27.7^{\circ} \mathrm{C}$ with an overall average of $18.7^{\circ} \mathrm{C}$. The soil and climate are like those in many highland areas in Ethiopia. It is an important town where most governmental institutions, national and international research centers are located. Cattle, small ruminant, poultry and equines are the major livestock species kept with fast growing smallholder dairy production. Currently the abattoir is one of the most facilitated modern export abattoirs in Ethiopia and is exporting meat of cattle and small ruminants. The study animals were all small ruminants brought to Abyssinia Slaughtering Service House for slaughter. Animals were grouped in to two categories as young and adult based on dentition standard given by Vatta [9]. In this study, animals were grouped in to young, which have not erupted permanent incisor teeth and one pair of permanent incisors (i.e. $<1$ year to $1 \frac{1}{2}$ years (for sheep) and $<1$ year to 2 years (for goats)). Those having two pairs and above permanent teeth (i.e. $=1 \frac{1}{2}$ years (for sheep) and $>2$ years (for goats) were grouped as adult. Body condition scoring was also carried out based on the handbook given by [10].

\section{Sample Size Determination and Sampling Procedures}

The total number of sheep and goat required for the study were calculated based on the formula given by Thrusfield [11]. The sample size was determined based on expected prevalence of $50 \%$, confidence interval of $95 \%$ and desired level of precision of $5 \%$. Accordingly, the sample size was 384 . But the sample size was raised to 1030 sheep and goats with the intention to increase the precision of the study. The sampling procedure were carried out using systematic random sampling in such a way that sampling units were selected at equal intervals with the first animal being selected randomly [11].

\section{Study Design}

Cross-sectional study was carried out from November 2017 to April 2018 to estimate the cause of liver condemnation and to calculate the direct financial loss due to condemnation in sheep and goats slaughtered at Abyssinia Slaughtering Service House.

\section{Study Methodology}

Ante mortem Inspection Randomly selected animals were subjected to routine ante mortem inspection during which various risk factors such as body condition, breed and age of animals were scored. The body condition score of animals were classified according to Nicholson \& Butter [12]. Accordingly, animals were grouped into poor, medium and good body conditioned. Estimation of age were carried out by examination of teeth eruption and categorized into young and adult. Ante-mortem examination was conducted on individual animals, while the animals were entering in to the lairage and in mass after they entered the lairage. Both sides of the animals were inspected at rest and in motion. Moreover, the general behavior of the animals, sign of diseases and abnormality of any type were recorded according to the standard ante mortem inspection procedures [13]. Following the judgment guideline by FAO, animals fit for human consumption were allowed for slaughter.

\section{Active Abattoir Survey}

Prior to sampling, a code was given on the skin, carcass, and visceral organ that corresponded to the code on live animal. During meat inspection, each organ of an animal was strictly and separately examined. A total of 1030 sheep and goats were inspected during ante mortem and postmortem examinations using standard examination procedures. During the ante mortem examination, general behavior, signs of disease, nutritional status, cleanliness and any type of abnormalities were recorded [14].

\section{Postmortem Examination}

During post mortem inspection, liver was thoroughly inspected by visualization, palpation and making systemic incisions where necessary for the presence of cyst, parasite and other abnormalities. Pathological lesions were differentiated and judged according to guidelines on meat inspection for developing countries and classified into the following categories of judgment namely: approved as fit for human consumption, conditionally approved as fit for human consumption, totally condemned as unfit for human consumption and partially condemned as unfit for human consumption [15].

\section{Assessment of Direct Financial Loss}

The financial loss due to liver condemnation was analyzed based on the average annual slaughter capacity of the abattoir, average market price of each liver and rejection rate of each liver. Average market price was determined based on the interview made with 30 personnel of the abattoir and different butchers. The financial loss due to condemnation of liver was estimated by the formula set by Ogunrinade [16]. As follows:

$$
E L=\Sigma s r x * \operatorname{Coy} * \operatorname{Roz}
$$

Where

EL=Annual economic loss estimated due to liver condemnation

$\Sigma$ srx=Annual sheep and goats slaughter of the abattoir 
Coy=Average cost of liver

Roz=Condemnation rates of liver

\section{Data Management and Analysis}

All raw data generated from this study were coded and entered in Micro Soft Excel spread sheet for data analysis; SPSS soft- ware version 20 were used. Descriptive statistics was used to determine the level of condemnation defined as proportion of liver condemned to the total number of livers examined. The variations between condemnation rates, age and body condition scores were evaluated by Pearson's Chi -square $\left(\mathrm{X}^{2}\right)$. The results of this study were considered statistically significant $(\mathrm{P} \leq 0.05)$.

Result

Table 1: Overall prevalence of small ruminant's liver condemnation in ASSH.

\begin{tabular}{|c|c|c|c|}
\hline Species & Total examined & Total positive & Prevalence (\%) \\
\hline Sheep & 520 & 255 & 49.04 \\
\hline Goat & 510 & 126 & 24.7 \\
\hline Total & 1030 & 381 & 37 \\
\hline$X^{2}=88.056$ & P-value $=0.000$ & & \\
\hline
\end{tabular}

The current finding revealed that from the total 1030 examined small ruminants' liver 381 (37\%) was condemned. A total of 520 sheep and 510 goats were examined at ASSH for the major causes of liver condemnation. Of these animals, the liver of 255 (49.04\%) sheep and 126 (24.7\%) goats was rejected due to various parasitic and gross pathological lesions (Table 1). The major causes of liver condemnation in the study abattoir were $92(8.9 \%)$ hepatitis, 66(6.4\%) calcification, 64(6.2\%) cirrhosis, 62(6.02\%) S. hepatica, 41(4\%) fasciola, 38(3.7\%) C. tenuicollis and $18(1.7 \%)$ adhesions (Table 2). From the total 520 sheep and 510 goat liver examined 255(49.04\%) and 126(24.7\%) sheep and goats' liver were condemned respectively (Table 1 ). Significantly higher rate of liver condemnation in sheep were recorded than goats $(\chi 2=$ 65.406; $\mathrm{p}=0.000$ ) (Tables $3 \& 4$ ).

Table 2: Species based causes of liver condemnation.

\begin{tabular}{|c|c|c|c|c|c|c|c|}
\hline \multirow{2}{*}{ Causes } & Hepatitis & Cirrhosis & Calcification & C.tenuicollis & $\begin{array}{c}\text { Stelesia hepat- } \\
\text { ica }\end{array}$ & Adhesion & Fasciola \\
\cline { 2 - 8 } & $56(10.8 \%)$ & $31(6.0 \%)$ & $47(9.04 \%)$ & $27(5.2 \%)$ & $47(9.04 \%)$ & $10(1.9 \%)$ & $37(7.1 \%)$ \\
\hline Sheep & $36(7.06 \%)$ & $33(6.5 \%)$ & $19(3.7 \%)$ & $11(2.2 \%)$ & $15(2.9 \%)$ & $8(1.6 \%)$ & $4(0.8 \%)$ \\
\hline Goats & $92(8.9 \%)$ & $64(6.2 \%)$ & $66(6.4 \%)$ & $38(3.7 \%)$ & $62(6.02 \%)$ & $18(1.7 \%)$ & $41(4.0 \%)$ \\
\hline Total & & & & & & & \\
\hline
\end{tabular}

Table 3: Association between origin, age and body condition with liver condemnation.

\begin{tabular}{|c|c|c|c|c|c|c|}
\hline \multirow[t]{3}{*}{ Condemnation Causes } & \multicolumn{2}{|c|}{ Origin } & \multicolumn{2}{|c|}{ Age } & \multicolumn{2}{|c|}{ Body condition } \\
\hline & Afar & \multirow{2}{*}{$\begin{array}{c}\text { Borana } \\
(n=462)\end{array}$} & Young & Adult & Medium & Good \\
\hline & $(n=568)$ & & $(n=334)$ & $(n=696)$ & $(n=511)$ & $(n=519)$ \\
\hline Hepatitis & $92(44.7 \%)$ & 0 & $39(30.5 \%)$ & $53(20.9 \%)$ & $31(15 \%)$ & $61(34 \%)$ \\
\hline Cirrhiosis & $54(26 \%)$ & $10(5.7 \%)$ & $23(18 \%)$ & $41(16.2 \%)$ & $46(23 \%)$ & $18(10 \%)$ \\
\hline Calcification & $25(12 \%)$ & $41(23.4)$ & $15(11.7 \%)$ & $51(20.2 \%)$ & $25(12 \%)$ & $41(23 \%)$ \\
\hline C.tenuicolis & $8(3.9 \%)$ & $30(17.14 \%)$ & $15(11.7 \%)$ & $23(9.09 \%)$ & $16(8 \%)$ & $22(12 \%)$ \\
\hline Stl.hepatica & $27(13 \%)$ & $35(20 \%)$ & $19(14.8 \%)$ & $43(17.0 \%)$ & $48(24 \%)$ & $14(7.8 \%)$ \\
\hline Adhesion & 0 & $18(10.3 \%)$ & $6(4.7 \%)$ & $12(4.74 \%)$ & $16(8 \%)$ & $2(1.1 \%)$ \\
\hline Fasciola & 0 & $41(23.4)$ & $11(8.6 \%)$ & $30(12 \%)$ & $19(9.5 \%)$ & $22(12.2 \%)$ \\
\hline Total & 206 & 175 & $128(38.3 \%)$ & $253(36.4 \%)$ & 201(39.3) & $180(34.7 \%)$ \\
\hline$\chi^{2}$ & & & & & & \\
\hline $\mathrm{P}$-value & & & & & & \\
\hline
\end{tabular}


Table 4: Summary of statistical result of the study.

\begin{tabular}{|c|c|c|c|c|c|c|}
\hline Variables & & $\begin{array}{l}\text { No. of animal } \\
\text { examined }\end{array}$ & $\begin{array}{l}\text { No. of positive } \\
\text { animal }\end{array}$ & Percent & $\mathrm{X}^{2}$ & $\mathrm{P}$-value \\
\hline Age & $\begin{array}{l}\text { Young } \\
\text { Adult }\end{array}$ & $\begin{array}{l}334 \\
696\end{array}$ & $\begin{array}{l}128 \\
253\end{array}$ & $\begin{array}{l}38.3 \\
36.4\end{array}$ & 0.377 & 0.539 \\
\hline Origin & $\begin{array}{c}\text { Afar } \\
\text { Borana }\end{array}$ & $\begin{array}{l}568 \\
462\end{array}$ & $\begin{array}{l}206 \\
175\end{array}$ & $\begin{array}{l}36.3 \\
37.9\end{array}$ & 0.284 & 0.594 \\
\hline Species & $\begin{array}{l}\text { Sheep } \\
\text { Goats }\end{array}$ & $\begin{array}{l}520 \\
510\end{array}$ & $\begin{array}{l}255 \\
126\end{array}$ & $\begin{array}{l}49.04 \\
24.7\end{array}$ & 65.406 & 0.000 \\
\hline Body condition & $\begin{array}{l}\text { Medium } \\
\text { Good }\end{array}$ & $\begin{array}{l}511 \\
519\end{array}$ & $\begin{array}{l}201 \\
180\end{array}$ & $\begin{array}{l}39.3 \\
34.7\end{array}$ & 2.391 & 0.122 \\
\hline
\end{tabular}

The major causes of liver condemnation in sheep were 56(10.7\%) hepatitis, 47(9.04\%) 47(9.04\%) Stelesia hepatica, calcification, 37(7.1\%) fasciola, 31(6\%) cirrhosis, 27(5.2\%) c. tenuicollis and 10 (1.9\%) adhesions. Likewise causes of liver condemnation in goats were $36(7.06 \%)$ hepatitis, $19(3.7 \%)$ calcification, 33(6.5\%) cirrhosis, 15(2.9\%) S. hepatica, 4(0.8\%) fasciola, $11(2.2 \%)$ C. tenuicollis and adhesions $8(1.6 \%)$ (Table 2). Totally 568 and 462 small ruminants included in the study were brought from Afar and Borana respectively. Liver condemnation was $206(36.3 \%)$ in small ruminants originated from Afar whereas $175(37.9 \%)$ in animals brought from Borana. Rate of liver condemnation was higher in animals from Borana, however statistically significant difference was not recorded in between animals originated from Afar and Borana $(\chi 2=0.284, \mathrm{P}=0.594)$ (Table 3). Out of 1030 sampled small ruminant's liver examined 128 (38.3\%) and 253 (36.4\%) young and adult liver were condemned due to pathological defects or presence of parasites. Slightly higher condemnation of liver recorded in young small ruminants than the adults, however it was not statistically significant $(\chi 2=0.377$, $\mathrm{P}=0.539$ ) (Table 3).

The study includes 511 medium and 519 good body conditioned small ruminants. Condemnation of liver on the body condition basis indicated higher rate was recorded in medium body condition animals 201(39.3\%) than good body condition $180(34.7 \%)$ small ruminants. The difference was not statically significant $(\chi 2=2.391 ; \mathrm{P}=0.122$ ) (Table 3). According to the current finding estimated financial loss due to liver condemnation at the study abattoir was 58,018.4 ETB or 2,148.8 USD. The annual slaughter rate of ASSH is 7600 sheep and 8400 goats, the average rejection rate of sheep liver and goat's liver at the abattoir in the current finding was $49.04 \%$ and $24.7 \%$ respectively. The average cost of sheep and goat liver during the study period was 25 ETB.

Annual slaughtered sheep at ASSH was 7600. On this study, from 520 samples 255 livers were totally condemned due to hepatitis, calcification, cirrhosis, stelesia hepatica, C.tenuicollis, fasciola and adhesion and from 7600 annually slaughtered animals average rejection rate was $49.04 \%$. One liver on local market costs 25 ETB. So, the financial losses of condemned liver due to hepatitis, calcification, cirrhosis, stelesia hepatica, C.tenuicollis, fasciola and adhesion from sheep were estimated to be 93,176 ETB or 3450.99
USD. On the other hand, annual slaughtered goats at ASSH were 8400. In the current study, 180 livers were totally condemned from a sample size of 510 . From 8400 annually slaughtered animals' average rejection rate was $24.7 \%$. One liver of goat on local market costs 10 Birr. So, the financial losses of condemned liver due to hepatitis, calcification, cirrhosis, stelesia hepatica, C. tenuicollis, fasciola and adhesion from goats were estimated to be 51,870 ETB or 1921.11 USD. The total financial loss due to small ruminant's liver condemnation in the abattoir was estimated to be 145, 046 ETB or 5372.1 USD.

\section{Discussion}

Meat inspection is commonly perceived as the sanitary control of slaughter animals and meat. The aim of meat inspection is to provide safe and wholesome meat for human consumption. Meat inspection and meat hygiene shall make sure that meat and meat products are safe and wholesome for human consumption [6]. In the present study, the major causes of liver condemnation in small ruminants slaughtered at Abyssinia Slaughtering Service House were hepatitis, calcification, cirrhosis, stelesia hepatica, fasciola, c. tenuicollis and adhesions. This finding is in line with, previous works [17-21]. The overall liver condemnation rate of this finding (37\%) is higher than previous findings of $16.63 \%$ by Jalelo \& Geremew, $34 \%$ by Bekele \& Szonyi [22]. However, it is lower than findings of $43.6 \%$ by Assefa, $48.7 \%$ by Addisu, $41.6 \%$ by Usman \& Belay [23], $42.3 \%$ by Aynalem [18], 76.8\% by Ezana [24] and $50.1 \%$ by Jibat [4].

Overall incidence of liver condemnation due to stelesia hepatica was $9.04 \%$ in sheep is similar with the findings of Aynalem \& Ejeta $[18,25,26]$. However, the current finding is higher than pervious works of $4.3 \%$ by Assefa et al., (2017) and lower than findings of Addisu which was $12.3 \%$. Similarly, goat's liver condemnation in the current finding due to stelesia hepatica $2.9 \%$ is lower than findings of Assefa [17], Addisu, Aynalem [18] 4\%, 20.7\% and $12.5 \%$ respectively. Losses from liver condemnation were assumed to occur since hepatic pathology is associated to infection that might have public health importance [19] and aesthetic value. The current finding due to hepatitis $10.8 \%, 7.06 \%$ is in line with $10.1 \%, 7.8 \%$, for sheep and goat respectively by Usman \& Belaye [23]. However higher than pervious works of 5.73\%, 5.99\% for sheep and goat respectively by Gezahagn and lower than findings 
of Mesfin \& Mekonnen [27], Ezana, Usman \& Belaye [23] which was $27.3 \%, 15 \% ; 19.3 \%, 23 \% ; 26 \%, 20 \%$; for sheep and goat respectively.

Species based rate of liver condemnation in the current finding is significantly higher in sheep $(49.04 \%)$ than goats $(24.7 \%)$. This finding agrees with the others reports. However this finding is not in agreement with the findings reported there were no species based statistical significant differences of liver condemnation $[7,23]$ The higher rate of parasitic causes of liver condemnation observed in sheep in comparison with goats could be due to their feeding behavior where sheep are usually grazers and goats tend to be more of browsers making them less exposed to the parasite [28].

Sheep liver condemnation due to hepatitis in this finding $10.8 \%$ is comparable with the finding of Usman and Belay (2016) $(10.1 \%)$, but lower than others finding and higher than the reports of $2.8 \%$ by Assefa [17]. Likewise, goat's liver condemnation due to hepatitis in this study is $7.06 \%$ is comparable with the findings of Addis et al. (2017) which is $7.7 \%$ and Usman \& Belaye [23] which is $7.8 \%$, on the other hand it is lower than others finding $23 \%$ by Ezana and higher than findings of $5.3 \%$ by Assefa [17], $4.7 \%$ by Ayenalem. The reason for the variation in the prevalence of hepatitis in those different places may be related with environmental situation in different areas.

Sheep liver condemnation due to calcification in this finding $9.04 \%$ is comparable with the finding of Mesfin \& Mekonnen [27] 11.9\% and Ayenalem 6.77\%. But lower than others finding $26.04 \%$ by Gezehagn; $14 \%$ by Ezana [24]. Likewise, goat's liver condemnation due to calcification in this study is $3.7 \%$ is comparable with the findings of Ayenalem. which is $4.95 \%$. On the other hand, it is lower than others finding $8.8 \%$ by Mesfin \& Mekonnen [27] and 18\% by Ezana [24].

Sheep liver condemnation due to fasciola in this finding (7.1\%) is comparable with the finding of Mesfin \& Mekonnen [27] $6.6 \%$ and Ayenalem 6.77\%. But lower than others finding 26.04\% by Gezehagn; $18.75 \%$ by Bayu [29] and higher than the reports of $0.22 \%$ by Hikmat [30],3.91 \% by Ayenalem. Likewise, goat's liver condemnation due to fasciola in this study is $(0.8 \%)$ is comparable with the findings of Hikmat [30]. which is $0.52 \%$. On the other hand, it is lower than others finding $4 \%$ by Mesfin \& Mekonnen [27], 3.1\% by Ayenalem and $2.26 \%$ by Bayu [29]. The higher fasciollosis in sheep than in goats was due to feeding habit in which sheep can exposed to larvae during grazing of harsh area while goats are more browser.

Age based rate of liver condemnation in the current finding is slightly higher in young (38.3\%) than adult (36.4\%). This finding is in line with the findings of Usman and Belaye. However, there were no age based statistically significant differences of liver condemnation and this finding is not in agreement with the findings reported by, Mesfin \& Mekonnen, Bayu \& Ezana [24,27,29]. This higher prevalence in young than adult small ruminants may be at- tributed to the higher susceptibility to both infectious and non-infectious causes of liver rejection in young than adult.

In young animal liver condemnation due to hepatitis in this finding $(30.5 \%)$ is comparable with the finding of Mesfin \& Mekonnen [27] 37.3\% and Ezana 27.8\%). But lower than others finding $48.7 \%$ by Usman and Belaye and higher than the reports of $14.3 \%$ by Gezehagn and $24.1 \%$ by Ayenalem. Likewise, in adult liver condemnation due to hepatitis in this study is $(20.9 \%)$ is comparable with the findings of Ezana [24] which is $15 \%$ and higher than the findings of Gezehagn which is $9.4 \%$. On the other hand, it is lower than others finding $44.2 \% \%$ by Mesfin and Mekonnen and $28.5 \%$ by Ayenalem.

Liver condemnation due to cirrhosis in young animal in this study $(18 \%)$ is comparable with the finding of $14.1 \%$ by Gezehagn, but higher than others finding $2.9 \%$ by Ezana [24] $8.5 \%$ by Mesfin \& Mekonnen [27]. Likewise, in adult liver condemnation due to cirrhosis in this study is (16.2\%) it is higher than others finding $5.6 \%$ by Mesfin and Mekonnen, 5.5\% by Ezana and $9.9 \%$ by Gezehagn. In young animal liver condemnation due to stelesia hepatica in this finding was $(14.8 \%)$ is comparable with the finding of Ashenafi $24.5 \%$ and Taye (2008) 25.8\%, but lower than other findings $56.6 \%$ by Usman and Belay (2016), 31.5\% by Mesfin and Mekonnen, $31.4 \%$ by Ayenalem and higher than the reports of $8.7 \%$ by Gezehagn, $8.74 \%$ by Ezana. Likewise, in adult liver condemnation due to stelesia hepatica in this study was $(17 \%)$ was higher than the findings of Gezehagn et al. (2017) 7.4\%, Ezana, (2008) 5.5\%. Similarly, it was lower than others finding 37.2\% by Mesfin and Mekonnen (2014), 41.5\% by Ayenalem, 27\% by Ashenafi and $72 \%$ by Usman and Belaye.

The higher prevalence was observed in the medium body conditioned animals $39.3 \%$ as compared to good body conditioned animals $34.7 \%$. This agrees with the previous works reported by Tsegeye \& Gebeyo [31], Bayu [29]. This variation may be due to management system and the pathologies of liver may led to reduction of the body weight and animals become medium weight. In the medium body conditioned animals, management system is extensive which leads to higher chance of exposure to infection and in good body condition the management system is intensive which leads to reduction of the chance of exposure to infections. The prevalence of infectious and non-infectious causes of liver rejection in slaughtered sheep and goats at ASSH which were found to be $36.3 \%$ from Afar origin animals and $37.9 \%$ from Borana animals. Even if the rate of liver condemnation was higher in animals originated from Borana than Afar it was not statistically significant. The current study agreed with prevalence reported 30.5\% by Mokonnen A and Muleta L. However lower than prevalence reported 69.53\%, 64.84\% Afar and Borana by Usman and Belaye. There was no significant difference in the prevalence among small ruminants from different sites of origin. This may be due to the similarity in the distribution of intermediate hosts and reservoirs among the different places from which the animals were brought. 
Lesions of infectious and non-infectious cases including cirrhosis, adhesion and calcification were the major causes for the condemnation of liver. Moreover, parasites namely Stelesia hepatica and fasciola species were found to be the important causes of liver rejection from international market. Likewise, previous works Jibat, Aseffa, Yimam and Jembere reported the importance of parasites as causes of organs condemnation resulting in higher financial loss.

The direct annual loss in ASSH due to rejection of affected livers due to various reasons was estimated to be 145, 046 ETB or 5372.1 USD from international market. According to this result financial loss associated with liver condemnation was higher than the finding of Helina [32], who reported 9790.01 ETB, financial loss in the AAAE. However, this estimate was lower than the estimate of Aynalem who done in Bishoftu, ELFORA Export abattoir and recorded annual loss of 79894.58 USD due to liver condemnation in small ruminants $[33,34]$. This may be due to slaughtering capacity, number of organs condemned of abattoir and difference in foreign currency.

\section{Conclusion and Recommendations}

Several diseases are the major concern to small ruminant farming as it causes extensive financial waste because of direct and indirect economic losses. In general, pathological conditions and parasitic diseases were the major causes of financial loss through liver condemnations at ASSH, which may also reflect the same scenario in other slaughter houses in Ethiopia. Proper meat inspections are essential to remove gross abnormalities from meat and its products [35-38]. Furthermore, it helps in the prevention of the distribution of contaminated meat those results in public health risk. In this study the condemnation of liver was found to be very immense. Hepatitis, calcification, cirrhosis, Stelesia hepatica, C. teniculosis, fasciola and adhesion were found to be major causes of liver condemnation in the abattoir. According to the result of this study, parasitic diseases and pathological conditions were the major causes of financial loss through liver condemnation at ASSH. Thus, result in extensive financial losses about 145, 046 ETB or 5372.1 USD per annum from direct economic losses. The present study indicated that a significant amount of money was lost due to diseases and abnormalities. Hence, this study may be valuable for the country by providing data in monitoring disease conditions and management practices of animals that have public health hazard and aesthetic value. Therefore, regular deworming of small ruminants and intermediate host and elimination of stray dogs should be practiced, further studies should be carried out in small ruminants that are going to be slaughtered in different abattoirs of the country and introduce preventive measures to reduce unnecessary financial losses encountered in the industry, small ruminants ranching at pastoral areas where the shoat population is vast should be put into practice for the purpose of export market and the total (exact) economic impact of the diseases of small ruminants at depth should be investigated.

\section{References}

1. CSA (2013) Agricultural sample survey, Report on Livestock and livestock characteristics (Private peasant holdings). Statistical Bulletin 570. Central Statistical Agency (CSA), Federal Democratic Republic of Ethiopia, Addis Ababa, Ethiopia.

2. PACE-Ethiopia (2003) Experiences and the way. Forward on community-based Animal Health Service delivery in Ethiopia. Proceedings of a workshop held in Addis Ababa, Ethiopia, p: 6.

3. Cadmus SIB, Adesokan HK (2009) Causes and implication of bovine organs/offal condemnations in abattoirs in western Nigeria. Trop Anim Health Prod 41(7): 1455-1463.

4. Jibat T, Ejeta G, Asfaw Y, Wudie A (2008) Causes of abattoir condemnation in apparently health slaughtered sheep and goats ssat HELMEX abattoir, Bishoftu, Ethiopia. Revue Vet Med 159(5): 305-311.

5. Alton GD, Lpeah D, Bateman KJ, McNab WB, Berk O (2010) Factors associated with whole condemnation rates in provincially inspected abattoir in Ontario 2001-2007: Implication for food animal syndromic surveillance. BMC Vet Res 6(42): 312-345.

6. Herenda D, Chambers PG, Ettriqui A, Seneviratna P, da Silva TJP (2000) FAO Animal Production and Health, Manual on Meat Inspection for Developing Countries, Food and Agriculture Organization of the United Nations, Rome, Italy.

7. Jobre Y, Lobago F, Tiruneh R, Abebe G, Dorchies PH (1996) Hydatidosis in three Selection Region in Ethiopia: An Assessment Trial on its Prevalence, Economic and Public Health Importance. Revue med Vet 147: 797-804

8. Amene F, Legesse E, Tesfaye D (2012) The cause, rate and economic implication of organ condemnation of cattle slaughtered at Jimma municipal abattoir, south western Ethiopia. Glob Vet 9(4): 396-400.

9. Vatta AF (2005) Goat and Sheep keepers' veterinary manual. Onderstepoort veterinary institute, private bag underreports, South Africa. 98: 26-30.

10. ESGPIP (2007) Body Condition Scoring of Sheep and Goats. Technical Bulletin p. 8.

11. Thrusfield M (2005) Veterinary epidemiology government department of Navy, Bureau 2 UK Blackwell science Ltd pp: 182-198.

12. Nicholson MJ, Butter MH (1986) A guideline to condition scoring of Zebu sheep and goats. International Livestock Center for Africa, Addis Ababa, Ethiopia.

13. Gracey JF (1999) Meat hygiene, ( $8^{\text {th }}$ edn), Bailleretindall, London, Philadelphia, Toronto, pp: 239-289.

14. Getaw A, Beyene D, Ayana D, Megersa B, Abunna F (2010) Hydatidosis: prevalence and its economic importance in ruminant slaughtered at Adama municipal abattoir, Central Oromia, Ethiopia. Acta Tropica 113: 221-225.

15. Getachew EW (2008) Major Diseases of Export Oriented Livestock in Export Abattoirs in/Around Ada Liben Woreda, Bishoftu. Online DVM Thesis, Faculty of Veterinary Medicine, Haramaya University, Ethiopia.

16. Ogunrinade A, Ogunrinade BI (1980) Economic importance of bovine fasciola in Nigeria. Trop Anim Health Prod 12: 155-160.

17. Assefa D, Gezaheng E, Abera B, Eticha E, Lemma D (2017) Major Cause of Organ and Carcass Condemnation in Apparently Healthy Small Ruminant Slaughtered at Addis Ababa Abattoir Enterprise, Ethiopia.

18. Aynalem M, Kassaye A, Birhanu H, Gezahegn A, Gemechu Ch (2015) Major Cause of Organ and Carcass Condemnation and Its Financial Loss at Bishoftu Elfora Export Abattoir. International Journal of Nutrition and Food Sciences. 4(3): 364-372. 
19. Assefa M (2005) Parasitic causes of carcass/organ condition at Asella Municipality abattoir. DVM thesis, Faculty of Veterinary Medicine, Addis Ababa University, Bishoftu, Ethiopia.

20. Yimam M (2003) Major causes of organ condemnation in ruminants slaughtered at Gondar abattoir, North West Ethiopia. Debre Zeit: Faculty of Veterinary Medicine, DVM Thesis, Addis Ababa University, Ethiopia.

21. Jembere S (2002) A survey of causes of organs/carcass condemnation in slaughtered cattle at Nazareth abattoir. Bishoftu: Faculty of Veterinary Medicine, Addis Ababa University, Ethiopia.

22. Bekele T, Szonyi B (2014) Study on the health status of sheep and goats and direct economic losses due to organs and carcass condemnation in Addis Ababa Municipal Abattoir Enterprise, Ethiopia. Abstract of technical report. Nairobi, Kenya, ILRI.

23. Usman B, Belay A (2016) Study on the Major Problems that Causes Carcass and Organs Condemnation and Associated Financial Losses at Elfora Export Abattoir, Bishoftu, Ethiopia Journal of Biology, Agriculture and Healthcare 6(9): 2224-3208.

24. Ezana G (2008) Major diseases of export-oriented livestock in export abattoirs in /around Ada Liben wereda, Debre Zeit: Faculty of veterinary medicine, Haramaya University, DVM Thesis, Ethiopia.

25. Ejeta G, Jibat T, Asfaw Y, Wudie A (2008) Causes of abattoir condemnation in apparently healthy slaughtered sheep and goats at HELMEX abattoir, DVM Thesis, Faculty of Veterinary Medicine, Haramaya University, Debre Zeit, Ethiopia.

26. Budke CM, Deplazes P, Torgerson PR (2006) Global socio-economic impacts of cystic Echinococosis. Emer infec Dis 12: 296-302.

27. Mesfn G, Mekonnen A (2014) Causes of Liver and Lung Condemnation among Apparently Healthy Slaughtered Sheep and Goats at Luna Abattoir, Modjo, Ethiopia. Middle-East J Scient Res 21: 2346-2351.

28. Mungube E, Bauni S, Tenhagen B, Wamae L, Nginyi J, et al. (2006) The prevalence and economic significance of fasciola gigantica and Stelesia hepatica in slaughtered animals in the semi-arid coastal Kenya. Tropical Animal Health and Production, 38: 475-483.

29. Bayu Y, Asmelash A, Zerom K, Ayalew T (2013) Prevalence and economic importance of liver parasites: Hydatid Cyst, Fasciola species and Cysticercus tenuicolis in sheep and goats slaughtered at Addis Ababa abattoir enterprise in Ethiopia.

30. Hikmat S (2014) A surveillance study on condemnation of ruminant's livers and lungs due to common disease conditions in Kerbala abattoirs. Kufa journal for veterinary medical science, 5(1): 22-30.

31. Tsegaye B, Gebeyehu (2015) Abattoir prevalence and severity of liver lesions in sheep slaughtered at Debre Birhan Municipal Abattoir, North East Ethiopia. International Journal of Agricultural Science Research. 4(4): 078-081.

32. Helina G, Tadesse G, Tewodros F, Mersha C (2012) Small ruminant Hydatidosis: occurrence and economic importance in Addis Ababa abattoir. Global Veterinaria 8(2): 160-167.

33. Ashenafi T (2010) Prevalence of Stilesia hepatica, fasciola species and Cysticercus tenuicolisin livers of sheep and goats slaughtered at HELMEX abattoir, Bishoftu, DVM Thesis, Faculty of veterinary medicine, Bishoftu, Addis Ababa University, Ethiopia.

34. Bekele M, Eliyas T, Alemayehu R, Rahmeto A, Fufa A (2010) Bovine cysticercosis in Cattle Slaughtered at Jimma Municipal Abattoir, South western Ethiopia: Prevalence, Cyst viability and Its Socio-economic importance. Veterinary World 3(6): 257-262.

35. Cadmus S, Adesokan H (2009) Causes and implications of bovine organs/offal condemnations in some abattoirs in Western Nigeria Trop Anim Health Prod, Nigeria 41(7): 1455-1463.

36. CSA, Central Statistical Authority (2008) Federal Democratic Republic of Ethiopia, Agricultural Sample Enumeration Statistical Abstract. DFEDB, Dessie Finance and Economic Development Bureau.

37. Mezegebu Y (2003) Major cause of organ condemnation in ruminants slaughtered at Gondor Abattoir, North Western Ethiopia. DVM thesis, Faculty of Veterinary Medicine, Addis Ababa University, Bishoftu, Ethiopia.

38. Taye S (2008) Cross-sectional study on the prevalence of Stilesia hepatica in small ruminant slaughtered at Mojo export abattoirs. Faculty of Veterinary Medicine, DVM Thesis, Bishoftu, Addis Ababa University, Ethiopia.

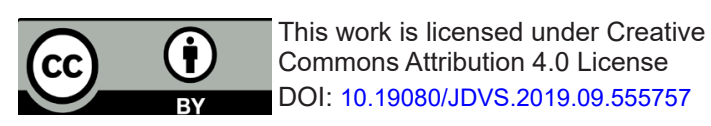

Your next submission with Juniper Publishers
will reach you the below assets
- Quality Editorial service
- Swift Peer Review
- Reprints availability
- E-prints Service
- Manuscript Podcast for convenient understanding
- Global attainment for your research
- Manuscript accessibility in different formats
( Pdf, E-pub, Full Text, Audio)
- Unceasing customer service
Track the below URL for one-step submission
https://juniperpublishers.com/online-submission.php

